\title{
El ex Balneario Popular Rocas de Santo Domingo (Chile): patrimonialización y musealización desde el vacío
}

\author{
Oscar Olivares Álvarez, Javiera Bustamante Danilo | Dpto. de Antropología, Universidad Alberto Hurtado \\ URL de la contribución <www.iaph.es/revistaph/index.php/revistaph/article/view/5044>
}

El tiempo pasado es una suma de acontecimientos superpuestos, y su recuerdo, una construcción que desde el presente hacemos no sin huecos, vacíos y silencios ${ }^{1}$. En la raíz de esa construcción se encuentran las materialidades; vestigios que en ocasiones pareciera ser lo único que sobrevive al paso del tiempo. De ahí ese afán memoralístico por recuperarlos y conservarlos, como si a través de ellos hablara ese pasado silenciado y desaparecido. ¿Acaso no son los impulsos de patrimonialización y musealización la constatación de que dichas materialidades consagran la posibilidad de narrar y transmitir ese pasado y que sin ellas el silencio y el olvido acecharían el presente? Si esto no fuera así, no tendríamos en Chile una larga lista de sitios que gracias al impulso de colectivos de derechos humanos han sido patrimonializados, es decir protegidos legalmente como patrimonio por el Estado. Algunos más notorios, otros más invisibles, nuestro repertorio es largo y ancho como nuestro país. Ahí, en una de las playas que conforman nuestra extensa franja de mar, se encuentra uno de estos sitios que sigue esperando indefinidamente por su musealización.

Ubicado en la comuna de Santo Domingo, V Región de Valparaíso, lugar de veraneo y turismo de la élite nacional y de tradición conservadora, el Balneario Popular Rocas de Santo Domingo representa un espacio de discordia en sus diferentes capas históricas. Inaugurado a fines de 1971 en el marco del Programa Inicial del Gobierno de la Unidad Popular "Educación Física y Turismo Popular", este conjunto de cabañas otorgó derecho al descanso a la clase trabajadora durante dos periodos de veraneo (1971-1972, 1972-1973) ${ }^{2}$ hasta que, luego del golpe de Estado de 1973, sus instalaciones fueron utilizadas para instruir a agentes de la Dirección de Inteligencia

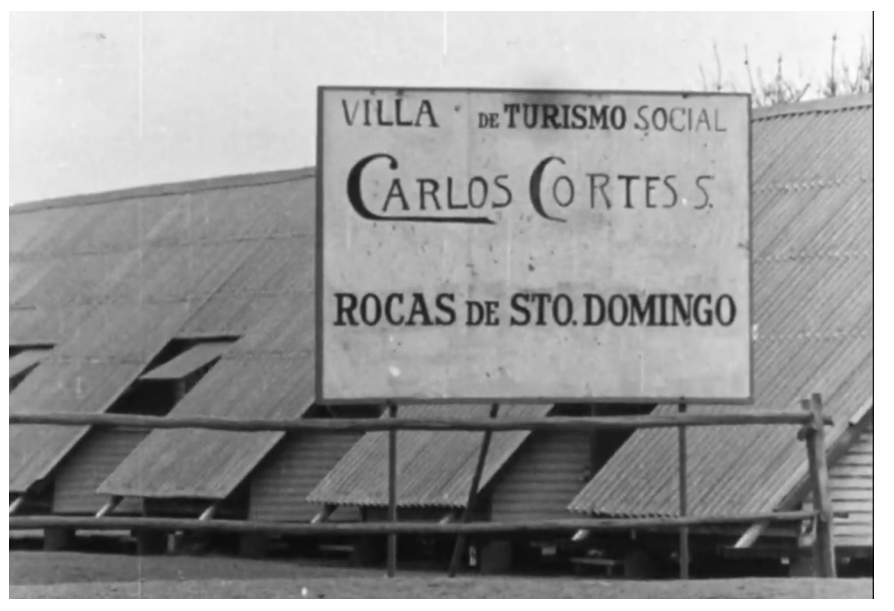

Balneario Popular Rocas de Santo Domingo | fuente Un verano feliz

Nacional (DINA), principal organismo represivo durante los primeros años de la dictadura cívico-militar. En 1978, pasó a manos de la Central Nacional de Informaciones (CNI), siendo utilizada simultáneamente como lugar de vacaciones de su personal y centro de detención clandestino ${ }^{3}$.

En 1990, recién iniciado el retorno a la democracia, fue transferida al Ejército de Chile, permaneciendo por más de 20 años en estado de abandono y restringiendo su entrada al público hasta que, en noviembre de 2013, en una acción coordinada de la Municipalidad de Santo Domingo y el Ejército de Chile, el complejo fue demolido y desmantelado, dejando solo los cimientos de lo que alguna vez fue un complejo turístico popular. Frente a este escenario y como medida de emergencia, sobrevivientes del recinto y otros actores simpatizantes consiguieron la protección de los cimientos restantes como Monumento Histórico el 12 de noviembre de 2014, bajo el decreto n. ${ }^{\circ} 337$ del Consejo de Monumentos Nacionales, 
lo cual significaba que el predio, en tanto patrimonio protegido, no podría ser vendido ni reutilizado para otros fines sin autorización. Sin embargo, desde entonces observamos que mientras en algunos bienes patrimoniales la protección garantiza una mirada atenta y cuidadosa del Estado, en otros se encuentran muy lejos de lograr esta atención y prioridad, lo que evidencia aquella paradoja propia de nuestra política patrimonial: que algunos patrimonios representan los idearios y narrativas conservadoras y merecen ser cuidados y protegidos, mientras que en otros bienes "incómodos" aquella atención se disuelve y la protección significa únicamente un título que no necesariamente garantiza su resguardo y conservación.

Bajo estas condiciones y a siete años de la protección de las cabañas de Santo Domingo como monumento histórico, una vista panorámica encuadra un sitio cuyos cimientos son constantemente pisados por ocasionales visitantes que, sin saber su historia, transitan sobre las ruinas en búsqueda de un humedal. La extracción de arenas de su orilla para alimentar una cercana playa de turistas ha tenido como efecto la grave y lenta erosión del borde que pausada y silenciosamente carcome los pocos vestigios que sobreviven. La indomable vegetación y las capas de basura cubren las ruinas del recinto. Solo el testimonio de sus sobrevivientes vuelve dicente

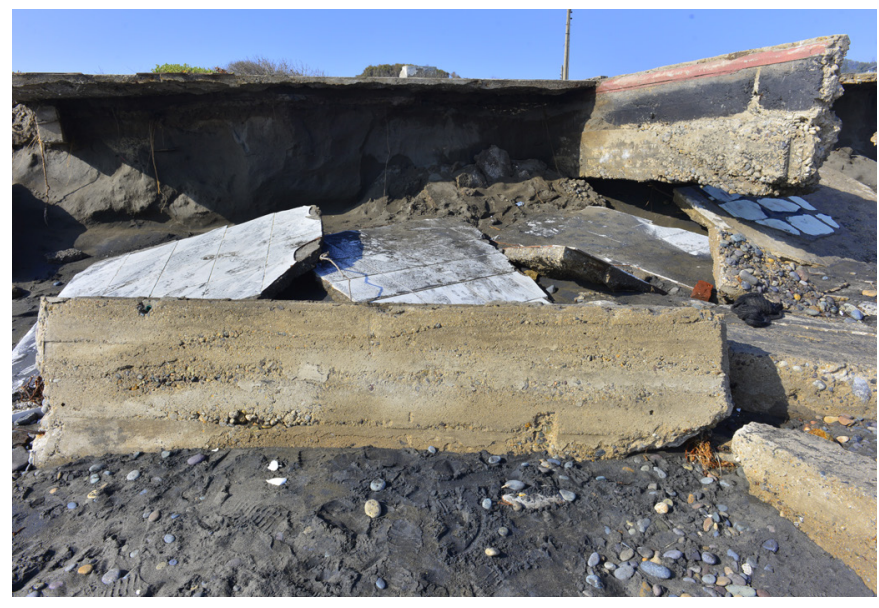

Fragmentos del sitio derrumbados a la orilla de la playa | foto Álvaro Hoppe, 2021

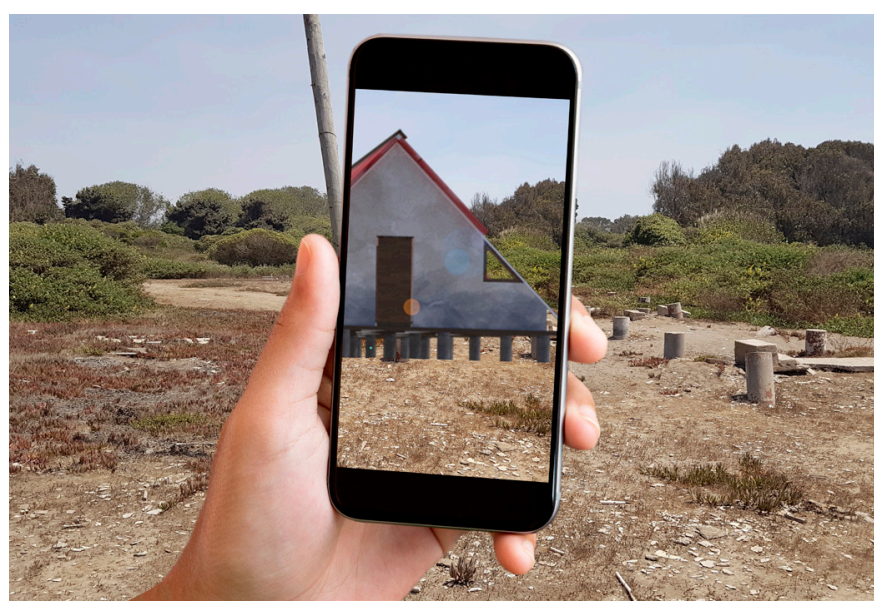

Visualización de una de las cabañas a través de la aplicación "Memorial Rocas" | fuente Memorialrocas.cl

al sitio y lo salva del olvido. En esta suerte de vaporización material nos preguntamos: ¿cómo musealizar y patrimonializar desde el vacío material y el abandono encarnadas en las ruinas que sobreviven en el sitio?

Ante esta situación, diferentes iniciativas han buscado hacer frente a lo que podría derivar eventualmente en la total desaparición del sitio. La Fundación por la Memoria San Antonio, encabezada por Ana Becerra, exprisionera y sobreviviente del recinto, ha levantado como principal estrategia de musealización la realización de recorridos testimoniales que vinculan la experiencia en primera persona con las diferentes capas históricas del lugar. Dirigidos a estudiantes escolares, universitarios y visitantes espontáneos, se ha construido un guión que articula los vestigios materiales que resistieron la demolición, el paso del tiempo y el actuar de la naturaleza, con la narración de los diferentes usos que solían tener, utilizando las huellas materiales como herramienta que activa la imaginación de los visitantes que buscan visualizar cómo fue alguna vez aquel complejo turístico. La segunda iniciativa, el proyecto Memorial Rocas AR, busca, a partir de una aplicación de realidad aumentada, reconstruir materialmente las instalaciones del complejo. Levantada por el realizador audiovisual Pepe Rovano, esta propuesta permite al visitante recorrer los vestigios del recinto y, a partir de una aplicación con teléfonos 
a debate Interpretación y gestión del patrimonio en los espacios del turismo oscuro

| coordinan Óscar Navajas Corral y Maribel Rodríguez Achútegui

inteligentes, visualizar las cabañas antes de ser demolidas. De esta manera, al apuntar con la cámara los lugares donde solía estar cada instalación, aún reconocibles por las huellas materiales distribuidas por el sitio, se visualiza una reconstrucción 3D de la edificación, complementada con material audiovisual, imágenes y testimonios de sobrevienes.

Lo cierto es que, más allá de cuestionar la evidente precariedad y asimetría de nuestra política patrimonial reflejada en el avanzado estado de deterioro y abandono del ex Balneario, nos interesa también problematizar los principios de integridad material que rigen el sistema de protección y valoración del patrimonio. ¿No son acaso esas ruinas tan históricas como las antiguas instalaciones hoy desaparecidas? ¿No nos habla ese abandono de una historia pos-protección que también forma parte de la historia del objeto patrimonial? En otras palabras, tras la constatación de una serie de patrimonios en abandono, derrumbe y olvido, ya sea producto de la acción humana o de la naturaleza, ¿no estamos en el momento clave de quebrar la ética patrimonial que prioriza y sacraliza los criterios de integridad y autenticidad como valores rectores únicos de la valoración y en consecuencia de la gestión del patrimonio? Las acciones memoriales frente al vacío material, como son los recorridos testimoniales y el proyecto de realidad aumentada mencionados, invitan a repensar no solo los esquemas de valoración de la pluralidad narrativa y funcional del patrimonio en la actualidad, sino también nos obliga a replantear el sistema de valores basado en los principios de integridad y autenticidad material que por años ha regido lo patrimonial. Las dinámicas que hoy se replican no solo en Chile sino a nivel global invitan a tomar el giro material del patrimonio como un punto de partida para disipar el régimen de autenticidad e historicidad material, haciendo eco del dinamismo propio que habita en el campo patrimonial.

\section{NOTAS}

1. Contribución elaborada en el marco del proyecto FONDECYT Iniciación n. 11200326 Destrucción, desafección y contranarrativas patrimoniales. Redefinición del patrimonio cultural en el Chile actual (2020-2023), financiado por la Agencia Nacional de Investigación y Desarrollo (ANID) de Chile.

2. Documento significativo sobre estos balnearios populares es Un verano feliz, cortometraje documental producido por el Departamento de Cine y Televisión de la Central Única de Trabajadores CUT (1972), con el objetivo de promover los Balnearios Populares, medida $\mathrm{N}^{\circ} 29$ del Programa de Unidad Popular, copia restaurada en 2021. Disponible en: https://unveranofeliz.cl/ [Consulta: 10/11/2021].

3. Más información en la web del Ministerio de Defensa Nacional del Gobierno de Chile (https://www.defensa. cl/temas-destacados/balneario-popular-rocas-de-santo-domingo/) y el diario El Desconcierto (https://www.eldesconcierto.cl/opinion/2021/06/16/marejadas-a-la-memoria-del-ex-balneario-popular-rocas-de-santo-domingo. html). 